87(10): 735-737

2. Sánchez JR, Gómez J, Escudero MC. Probable ticlopidine-induced severe aplastic anemia and cholestatic hepatitis. Haematologica 1997; 82(5): 639.

3. Sanjuan F, Jiménez J, Naya J, Fuentes F. Hepatitis colestásica por ticlopidina: presentación de un nuevo caso. An Med Interna 1997; 14 (10): 540-541.

4. Artímez ML, Fernández E, Rodríguez M, González M, Rodrigo L. Hepatitis tóxica por ticlopidina. Tres nuevos casos. Rev Esp Enf Digest 1997; 89 (10): 796-797.

5. Bruguera M. Hepatitis colestásica asociada a ticlopidina. Gastroenterol Hepatol 1997; 20 (3): 163-164

6. Roy L, Plante M A, Perreault H, Biron P. Cholestatic hepatitis: ticlopidine suspected. Thérapie 1995; 50: 593-594.

7. Aleva RM, Wouters B, Kraan J, Postmus PE. Late onset asthma? Eur Respir J 1991; 4: 239-241.

\section{Endocarditis por cable de marcapasos}

\section{Sr. Director:}

La endocarditis relacionada con la infección del cable del marcapasos, es una complicación rara asociada a los marcapasos endocavitarios. La incidencia de endocarditis que aparece tras la implantación de un marcapasos endocardial permanente oscila entre el $0,13 \%$ y el 19,9\% (1). La historia natural de la infección en algunos casos es sombría, con un porcentaje de mortalidad alto, entre un 30-35\%, según diferentes estudios $(2,3)$. A continuación presentamos el caso de una paciente con endocarditis por cable de marcapaso en la que fue necesaria la extracción del mismo.

Mujer de 60 años con antecedentes de diabetes mellitus tipo 2 e hipertensión arterial. Ingresada dos años antes por bloqueo A-V Mobitz II con implantación de marcapasos definitivo DDD. Al año de ser colocado el marcapaso es ingresada por cuadro de trombosis venosa profunda en extremidad superior derecha asociada al cable del marcapasos, desde entonces recibe tratamiento con dicumarínicos. Consulta por cuadro de fiebre de un mes de evolución que ha sido tratado como infección de vías respiratorias con tratamiento antibiótico por vía oral (VO) sin mejoría. A su ingreso, la paciente se encuentra febril $\left(\mathrm{T}^{\mathrm{a}} 37,8^{\circ} \mathrm{C}\right)$, auscultación cardíaca con tonos rítmicos a 60 latidos por minuto, sin soplos. Auscultación pulmonar con algún roncus aislado. Abdomen muy globuloso, sin hallazgos significativos. Analíticamente destaca una Hgb de 10,2 g/dL, Hto $30,3 \%, 13.000$ leucocitos (70\% neutrófilos). VSG de 80 $\mathrm{mm} / 1^{a}$ hora y una Proteína C Reactiva (PCR) de $2.6 \mathrm{mg} / \mathrm{dL}$. Radiografía de tórax, se aprecia cable de marcapasos y generador. Radiografía de abdomen normal. Los hemocultivos resultaron negativos. Con la sospecha de endocarditis por cable de marcapaso se inicia tratamiento antibiótico con cefuroxima $(1,5 \mathrm{~g} \mathrm{c} / 8 \mathrm{~h} \mathrm{IV})$ y rifampicina $(300 \mathrm{mgc} / 12 \mathrm{~h} \mathrm{VO})$. En la ecografía transtorácica no se aprecian vegetaciones, por lo que se realiza ecografía transesofágica, hallándose en el cable que va a la aurícula derecha en el tramo proximal tres mamelones de un centímetro de diámetro, sugestiva de endocarditis por cable de marcapaso. Con la confirmación ecográfica de endocarditis se decide retirar los electrodos junto con el generador bajo circulación extracorpórea (CEC) y colocación de un marcapasos definitivo epicárdico . Los cultivos del cable del marcapaso resultaron negativos. Tras la intervención y dada su buena evolución, se decide su alta con cefuroxima (500 mg/12h vía oral).

A los dos días ingresa de nuevo por cuadro de disnea brusca. A la exploración se encuentra sudorosa con taquipnea (35 r.p.m.). A la auscultación pulmonar no se aprecian estertores.
La radiografía de tórax y el electrocardiograma son normales. Se realiza gammagrafía pulmonar de ventilación / perfusión que muestra imágenes de alta probabilidad para tromboembolismo de pulmón. El hemograma, bioquímica y coagulación fueron normales excepto una VSG de $100 \mathrm{~mm} / \mathrm{h}$ y una PCR de 15 $\mathrm{mg} / \mathrm{dL}$. La ecografía doppler de extremidades inferiores no mostró hallazgos a nivel del sistema venoso profundo. Tras administración de heparina IV mejora del cuadro, siendo dada de alta con tratamiento con dicumarínicos. La paciente mantiene el tratamiento antibiótico durante un mes, y en controles posteriores al mes y a los seis meses la paciente se encuentra asintomática.

El diagnóstico de endocarditis por cable de marcapasos es difícil y debería ser considerado de forma sistemática en todos los pacientes portadores de marcapasos que presenten fiebre, infección en el lugar de implantación cutánea del mismo, o patología pulmonar (3). La ecografía transtorácica es poco sensible para la demostración de vegetaciones en el cable del marcapasos, mientras que la ecografía transesofágica las muestra en un alto porcentaje, cercano al $95 \%$ de los pacientes con vegetaciones a nivel del cable del marcapasos (4). Estando esta superioridad de la ecografía transesofágica recogida en numerosos estudios $(3,4)$, ratifica que es el método más adecuado para el diagnostico de vegetaciones a nivel del cable del marcapasos.

Los Staphylococcus son los causantes de la gran mayoría de estas infecciones (80-90\%) (5), la alta incidencia de infección por Staphylococcus confirma la necesidad de terapia antiestafilocócica empírica en todos los casos (3).

Un dato importante que también se ha observado (6), es la presencia de un alto porcentaje de pacientes con inmunosupresión previa, como es la diabetes mellitus. Otros factores predisponentes descritos en otros trabajos y que predisponen a esta infección son la edad, neoplasias, tratamiento con fármacos inmunosupresores, alcoholismo y la insuficiencia renal crónica (3).

En nuestra experiencia, así como en otros estudios recogidos en la literatura (7), la terapia con antimicrobianos solos, sin la extracción del sistema del marcapasos, no estaría indicada por el alto porcentaje de recidiva de la infección tras la retirada de los antibióticos, por lo que creemos necesaria la retirada inmediata del sistema del marcapasos desde el primer momento, junto con una prolongada terapia con antimicrobianos, si se quiere controlar la infección sistémica.

\section{B. Sánchez Sierra, R. Baños Madrid, E. Andreu, J. García- Estañ, J. Gómez Gómez}

Servicio de Medicina Interna-Infecciosas. Hospital Universitario Virgen de la Arrixaca. Murcia

1. Victor F, de Place C, Leclercq C, Camus C, Gras D, Le Helloco A, et al Infections occurring on permanent endocavitary pacemaker leads: values of transesophageal echocardiography. Arch Mal Coeur Vaiss 1995; 88: 1875-1881.

2. Graux P, Lequeuche B, Guyomar Y, Carlioz R, Delfaut P, Beaugeard D, et al. Multifactor prevention of endocarditis and cardiac pacemaker. A prospective study apropos of 207 patients. Ann Cardiol Angeiol (Paris) 1996; 45: 113-118.

3. Klug D, Lacroix D, Savoye C, Goullard L, Grandmougin D, Hennequin $\mathrm{JL}$, et al. Systemic infection related to endocarditis on pacemakers leads. Circulation 1997; 95: 2098-2107.

4. Barbetseas J, Lalos S, Kyriakidis M, Aggeli C, Toutouzas P. Role of transesophageal echocardiography in the diagnosis of infected retained pacing lead. Pacing Clin Electrophysiol 1998; 21: 1159-1161.

5. Climent V, Martinez JG, Marín F, Meseguer J, Sogorb F. Natural valve endocarditis in patients pacemakers. Rev Clin Esp 1999; 199: 28-30.

6. Arber N, Pras E, Copperman Y, Schapiro JM, Meiner V, Lossos IS, et al Pacemaker endocarditis. Report of 44 cases and review of the literature. 
Medicine 1994; 73 (6): 299-305.

7. Bohm A, Banyai F, Preda Y, Zamolyi K. The treatment of septicemia in pacemaker patients. Pacing Clin Electrophysiol 1996; 19 (7): 1105-1111.

\section{Infección por Mycobacterium avium en paciente con SIDA}

\section{Sr. Director:}

El Mycobacterium avium intracelulare (MAC) es un microrganismo ubicuo de distribución geográfica universal. Se puede aislar de multiples fuentes. Su puerta de entrada es el tracto respiratorio y sobre todo gastrointestinal. La infección diseminada por MAC era un hallazgo excepcional antes de la aparición del SIDA. En pacientes con SIDA el único factor de riesgo reconocido es el grado de inmunodepresión $(1,2)$. Aunque se han descrito formas localizadas en multiples niveles del organismo, afecta sobre todo el aparato digestivo siendo rara la afectación pulmonar (3). El tratamiento recomendado esta basado en combinacíones de claritromicina y etambutol.

Con la llegada de los tratameintos antirretrovirales de alta eficacia ha disminuido claramente su incidencia al tiempo que se ha modificado su espectro clínico (4). Describimos el caso de un paciente VIH con infección por MAC localizada en pulmón y mediastino.

Varón de 32 años interno en un centro penitenciario. VIH conocido desde hace seis meses. NO ADVP. Heterosexual promiscuo. Inicio tratamiento antiretroviral tres semanas antes con D4t/ 3TC, indinavir y cotrmoxazol profilactico siendo en ese momento su carga viral 100.000 copias y sus cd4 24 celulas/microlitro. Ingresa en nuestro servicio por objetivarse en una radiografía un infiltrado intersticial bilateral y adenopatías hiliares. Refería tos con escasa espectoración desde hacía dias sín disnea, dolor torácico o hemoptisis. No presentó fiebre hasta el día anterior al ingreso siendo en ese momento la temperatura de $39^{\circ}$. Exploración: buen estado general, consciente y orientado.

Cabeza y cuello, no Muguet, no adenopatías. Torax: crepitantes en bases y auscultación cardíaca normal. Abdomen y extremidades sin hallazagos.

Exploraciones complementarias: $\mathrm{T}^{\circ} 36,5$. HB: $10,1 \mathrm{mg} / \mathrm{dl}$ Hto: 32,5. VCM 86 fl. Plaquetas 429.000/Microlitro. Leucocitos $9.230 \times 1000 /$ microlitro (7940 neutrofilos, 470 linfocitos, 540 monocitos, 160 eosinófilos). Glucosa $87 \mathrm{mg} / \mathrm{dl}$. LDH 343 UI/I. GOT 3 UI/I. GPT 33 UI/I. GGT 48 UI/I. A 187 UI/L. Bilirrubina total $0,87 \mathrm{mg} / \mathrm{dl}$. Proteínas totales $7,4 \mathrm{Gr} / \mathrm{dl}$. Albumina 2,84 $\mathrm{Gr} / \mathrm{dl}$, Creatinina $1,13 \mathrm{~m} / \mathrm{dl}$, Calcio 1,13 m/dl. Fósforo 4,3 mg/dl, úrico 6,4 mg/dl. Colesterol $143 \mathrm{mg} / 100$. Triglicéridos 148 $\mathrm{mg} / 100$. Actividad de protrornbina $71 \%$, APTT 39,9\%. Gasometria arterial basal: ph 7,47, pO2 $77 \mathrm{mmHg}, \mathrm{pCO} 22,1 \mathrm{mmHg}$, bicarbonato 15,5 Mmol/1 SAT 96,5 \%. Serología a lues, toxopasma IgG y hepatitis C negatíva. AgHbs -, AcHBc +, AcHBc + Radiografía de torax: infiltado intersticial bilateral y adenopatías hiliares. TAC toracoabdominal: bloque adenopático en localización paratraqueal derecha que se extiende hasta la altura del cayado aórtico. Adenopatías paraaórticas izquierdas y en hilio pulmonar derecho. Patrón intersticial en forma de vidrio deslustrado en disposición parcheada con afectación predominantemente de pulmóm derecho, hiado, par creast bazo, via biliar, suprsrenal y riñones normales. No adenopatías intraabdominales. 3AAR de esputo seriados. Broncoscopia: aspecto macroscópico normal. Cultivo del lavado broncoalveolar negativo para bacterias, micobacterias y hongos. Tinción para Pneumocistis carinii, citología para celulas malignas. Biopsia transbronquial: moderada fibrosis septal. Punción transcarial: inflamación granulomatosa. Medias- tinoscopia con biopsia ganglionar: adenitis granulomatosa caseificante. En la muestra de ganglio mediastínico se informa crecimiento de MAC instaurándose en ese momento tratamiento con claritromicina y etambutol.

Tras la introducción del tratamiento antiretroviral de alta eficacia en el manejo del SIDA, la infección por MAC ha visto modificado su espectro clínico en pacientes VIH. Se han descrito cuadros de linfadenitis focales (cervicales, torácicas o abdominales), fiebre elevada y leucocitosis en las primeras semanas tras la introducción del tratamiento antiretroviral. Estos cuadro serían consecuencia de la recuperación de la capacidad de respuesta imflamatoria ante una infección preexistente pero subclínica por MAC en individuos muy deteriorados inmunológicamente (4).

En resumen, tras la introducción del tratamiento antiretroviral de alta eficacia, ha cambiado la frecuencia y forma de presentación de las complicaciones infecciosas o no de la infección por VIH. Así ante un paciente VIH con sintomatología pulmonar, patrón intersticial y adenopatias hiliares que ha comenzado recientemente con tratamiento antiretroviral, deberíamos descartar la infección por MAC.

\section{J. Sánchez Ayuso, S. Mateo Álvarez}

Servicio de Medicina Interna. Unidad de Acceso Restringido. Hospital 12 de Octubre. Madrid

1. Nlghtingale SD, et al. Incidence of Mycobacterium avium-intracellulare complex bacteriemia in human immunodeficency virus-positive patients. J Infect Dis 1992; 165: 1082-1088.

2. Jacobson MA, et al. Natural History of diseminated Mycobacterium avium complex infections in AIDS. J Infect Dis 1991; 164: 994-998.

3. Gordin FM, et al. Early manifestation of disseminated Mycobacterium avium complex disease: A prospective evaluation. J Infect Dis 1997; 176: 126-132.

4. Race EM, et al. Focal mycobacterial lymphadenitisfollowing initiation of protease inhibitor therapy in patients with advanced HIV disease. Lancet 1998; 351: 252-255.

Hemoptisis amenazante en el aneurisma de aorta. A propósito de un caso con supervivencia prolongada

\section{Sr. Director:}

La hemoptisis amenazante representa menos del 5\% de todos los casos de hemoptisis. Sin embargo, por su alta mortalidad obliga a adoptar medidas diagnósticas (broncoscopia) y terapéuticas urgentes (embolización de las arterias bronquiales o resección quirúrgica), con el fin de controlar el sangrado activo. Las causas más frecuentes son la tuberculosis, las bronquiectasias y el cáncer de pulmón (1). El aneurisma de aorta es una causa poco común de hemoptisis amenazante, que se acompaña de una elevada mortalidad cuando no se diagnostica e indica un tratamiento quirúrgico precoz, siguiendo un protocolo de actuación diferente a otros pacientes con hemoptisis amenazante (2).

Debido a su rareza y a la supervivencia excepcionalmente prolongada, presentamos el caso de un anciano con hemoptisis amenazante por un aneurisma de aorta que sigue vivo después de 18 meses, junto a una revisión de la literatura.

Se trata de un varón de 76 años que ingresa en nuestro servicio en noviembre de 1999, por hemoptisis amenazante $(>200 \mathrm{ml}$ en menos de 12 horas). Entre los antecedentes destacaban hiperten- 